\title{
FENOMENOLOGIA E PSICOLOGIA DA SAÚDE: UMA ANÁLISE DA PRODUÇÃO ACADÊMICA BRASILEIRA
}

\author{
Phenomenology and Health Psychology: a Review of Brazilian Academic Production
}

Fenomenología y Psicología de la Salud: una Revisión de la Producción Académica de Brasil

\begin{abstract}
Resumo: O objetivo deste trabalho é investigar as contribuições da Fenomenologia para a Psicologia da Saúde a partir da produção acadêmica brasileira. A pesquisa foi realizada nas bases de dados SciELO (Scientific Eletronic Library Online), PePSIC (Periódicos Eletrônicos em Psicologia) e LILACS (Literatura Latino-Americana e do Caribe em Ciências da Saúde), sendo selecionados e analisados treze artigos, publicados entre 2000 e 2018. Constatou-se que a Fenomenologia contribui de várias maneiras, enquanto epistemologia de Edmund Husserl, como abordagem que apresenta uma visão de ser humano e de mundo através de vários fenomenólogos, como método fenomenológico filosófico adaptado à Psicologia por diversos autores. Em Psicologia da Saúde, as pesquisas revelam uma compreensão do processo saúde-doençacuidado tanto através da análise das experiências vivenciais de usuários que buscam os serviços de saúde, quanto pela atuação do profissional psicólogo com predomínio da visão biopsicossocial. Revela-se uma pluralidade de concepções teóricas e percursos metodológicos tanto em Fenomenologia como em Psicologia da Saúde, sendo promissor o avanço de pesquisas em Psicologia da Saúde através das contribuições advindas da Fenomenologia.
\end{abstract}

Palavras-chave: Psicologia da Saúde; Fenomenologia; Psicólogos; Produção acadêmica.

\begin{abstract}
This study aimed to investigate the contributions of Phenomenology to Health Psychology based on Brazilian academic production. A search in the SciELO (Scientific Electronic Library Online), PePSIC (Electronic Psychology Journals) and LILACS (Latin American and Caribbean Health Sciences Literature) databases was performed and thirteen papers published between 2000 and 2018 were selected and analyzed. It was found that Phenomenology contributes in many ways while Edmund Husserl's epistemology, as well as an approach that presents a view of the world and human beings by means of a number of phenomenologists, and as a philosophical phenomenological method adapted to Psychology by various authors. As far as Health Psychology is concerned, research brings an understanding of the health-disease-care process both by the analysis of the experiences of users who turn to health services as well as by professional psychologists' practice within a biopsychosocial perspective. A plurality of theoretical conceptions and methodological pathways is observed both when it comes to Phenomenology and Health Psychology, thus further studies on Health Psychology stemming from the contributions of Phenomenology are promising.
\end{abstract}

Keywords: Health Psychology; Phenomenology; Psychologists; Academic production.

Resumen: El objetivo de este trabajo es investigar las contribuciones de la Fenomenología a la Psicología de la Salud a partir de la producción académica nacional. La investigación fue realizada en las bases de datos SciELO (Scientific Eletronic Library Online), PePSIC (Periódicos Electrónicos en Psicología) y LILACS (Literatura Latinoamericana y del Caribe en Ciencias de la Salud), siendo seleccionados y analizados trece artículos, publicados entre 2000 y 2018 . Se constató que la Fenomenología contribuye de varias maneras como epistemología de Edmund Husserl; como enfoque que presenta una visión de ser humano y de mundo a través de varios fenomenólogos; como método fenomenológico filosófico adaptado a la Psicología por diversos autores. En Psicología de la Salud, las investigaciones revelan una comprensión del proceso salud-enfermedad-cuidado tanto a través del análisis de las experiencias vivenciales de usuarios que buscan los servicios de salud, como por la actuación del profesional psicólogo con predominio de la visión biopsicosocial. Se revela una pluralidad de concepciones teóricas y recorridos metodológicos tanto en Fenomenología como en Psicología de la Salud, siendo promisor el avance de investigaciones en Psicología de la Salud a través de las contribuciones provenientes de la Fenomenología.

Palabras-clave: Psicología de la Salud; la Fenomenología; Psicólogos; la Produccíon académica.

\section{Introdução}

A Psicologia da Saúde é um campo de desenvolvimento recente, cuja gênese diz respeito à interface Psicologia e Saúde. A American Psychological Association (APA, 2003) foi a primeira associação de psicólogos a criar um grupo de trabalho no campo da saúde, em 1970, bem como a publicar a primeira revista oficial, Health Psychology, em 1982
(Almeida \& Malagris, 2011; Castro \& Bornholdt, 2004). Uma das primeiras tentativas de conceituar esse campo específico da Psicologia em distinção à medicina comportamental foi realizada por Matarazzo, primeiro presidente do periódico Health Psychology, vinculado à APA (Angerami- Camon, 2011; Roso, 2007). Segundo ele, Psicologia da Saúde são "contribuições educacionais, científicas e 
profissionais específicas da disciplina da psicologia para a promoção e manutenção da saúde, a prevenção e o tratamento de doenças, e a identificação dos correlatos etiológicos e diagnósticos de saúde, enfermidade e disfunções relacionadas". (Matarazzo, 1980, p. 815, tradução nossa).

A definição clássica foi complementada com os dizeres: "e à análise e melhoramento do sistema de saúde e à formação de políticas de saúde" (Matarazzo, 1982, p. 4, citado por Roso, 2007, p. 86). Ribeiro (2011) destaca a amplitude dessa definição, a qual abrange os afazeres no geral do sistema de saúde. Assim, uma das características da Psicologia da Saúde, segundo esse autor, é o foco na dimensão de saúde em vez da doença.

Sebastiani (2011) apresenta o percurso histórico da Psicologia da Saúde na perspectiva latinoamericana. Ele mostra que havia insuficiente incorporação dos psicólogos nos setores de saúde; além disso, destaca limites sobre a formação profissional em pós-graduação e problemas quanto às pesquisas, visto que os resultados delas não ofereciam soluções práticas aos problemas de saúde. Ademais, o autor sublinha o aumento da atuação do psicólogo nesse campo e o trabalho em equipes interdisciplinares. Por fim, destaca que a Psicologia da Saúde avançou na promoção de saúde e prevenção de doenças para além de seu diagnóstico e tratamento .

Isso posto, abordaremos algumas especificidades quanto à compreensão de Psicologia da Saúde diante da diversidade de influências de outras áreas e de concepções distantes entre alguns autores, quais sejam: a ênfase na mudança de comportamento, sua proximidade a modelos de Psicologia Clínica e a relação entre Psicologia da Saúde e Psicologia Hospitalar.

Na década de 90, a ênfase nas mudanças comportamentais do indivíduo para a manutenção da saúde foi tanto destaque em publicações da área (Rodríguez-Marín, 1995; Rodríguez \& Garcia, 1996) quanto alvo de críticas, por ser "uma concepção de saúde pessimista (baseada na doença), limitada (visa mudar comportamento/atitude), individualizante e discriminatória (atende diferenciadamente as pessoas)" (Roso, 2007, p. 87).

Nos anos 2000, ganhou destaque a discussão da interface entre a Psicologia da Saúde e as Psicologias Clínica e Social. Cruz e Cunha (2015) destacam que a Psicologia Clínica contribuiu de forma técnica enquanto campo de saúde. Por outro lado, a ruptura se fez necessária devido à ênfase na formação clínica psicanalítica com visão do sujeito como um ser a-histórico, dissociado do seu contexto sociocultural e sob a ótica do modelo biomédico na análise do sujeito (Spink, 2003). Essa autora cunhou o termo "Psicologia Social da Saúde", por permitir um olhar mais coletivo, com a inclusão da perspectiva da cidadania como indissociável das ações de saúde, as quais devem considerar aspectos individuais e sociais
(Alves, Santos, Ferreira, Costa, \& Costa, 2017; BiagiBorges, Tonon, Scorsolini-Comin, \& Peres, 2015).

Contudo, há, no Brasil, certa confusão entre Psicologia da Saúde e Psicologia Hospitalar, o que não ocorre no resto do mundo. Castro e Bornholdt (2004), Ribeiro (2011) e Rumin (2013) defendem que a Psicologia Hospitalar é uma subárea da Psicologia da Saúde no Brasil. Para Castro e Bornholdt (2004) e Ribeiro (2011), aquela nomeia o campo de atuação hospitalar, enquanto essa faz referência às práticas desenvolvidas. Já Castro e Bornholdt (2004) e Rumin (2013) elucidam que a Psicologia da Saúde envolve a atenção à saúde globalmente, conforme a política do Sistema Único de Saúde (SUS), enquanto a outra não engloba a atenção primária, por exemplo. Por fim, o Conselho Federal de Psicologia (CFP, 2007) instituiu a Psicologia Hospitalar como área de especialização da Psicologia e não da Psicologia da Saúde.

Diante do contexto histórico e das nuances no desenvolvimento do campo, verificamos uma pluralidade de concepções, além de influências de outras vertentes da Psicologia, para se pensar a identidade da denominada Psicologia da Saúde. Para Witter (2008), a Psicologia da Saúde busca a promoção do bem-estar físico, mental e social do indivíduo, considerando-o em seu contexto interacional e como um ser histórico, o que pressupõe uma compreensão multifatorial do processo saúde-doença-cuidado. De forma complementar, para Alves et al. (2017), a Psicologia da Saúde é um campo autônomo com foco na saúde dos indivíduos em seus meios sociais, buscando a promoção da saúde e a prevenção de enfermidades, ou seja, com primazia à atenção primária da saúde.

Sobre a concepção de saúde-doença, a Organização Mundial da Saúde (OMS) reconheceu, em 1948, a promoção e proteção de saúde como direito de todos e obrigação do Estado (Batistella, 2007; Scliar, 2007). Esse conceito de saúde, aceito internacionalmente, segundo Batistella (2007), compreende "um completo estado de bem-estar físico, mental e social e não apenas a ausência de doença ou enfermidade” (p. 57). A partir desse conceito, poder-se-ia estruturar um sistema nacional de saúde nos diversos países, adaptado às realidades socioculturais, econômicas e políticas, e direcionado ao cuidado. Cuidar, do grego arcaico mérimna, que significa um modo que permite conservar a vida, faz parte do existir humano, no intuito de conservá-la, protegendo-a de sua própria debilidade (Mortari, 2018). Essa visão é criticada por ser idealista e pela possibilidade de o Estado intervir na vida dos cidadãos, o que contribuiu para a definição de saúde como ausência de doença, proposta por Christopher Boorse citado por Scliar (2007), numa perspectiva do modelo biomédico.

No campo de estudos sobre o processo saúdedoença, o conceito de promoção de saúde, originário no princípio do século XX e atribuído a Henry 
Sigerist, apontava para ações de cunho educativo para garantir qualidade de vida à população. Após a Segunda Guerra Mundial, a promoção de saúde, associada à Medicina Preventiva, ganhou status de prevenção primária, ou seja, foi entendida como um conjunto de ações voltadas para proteger as pessoas do adoecimento (Demarzo, \& Aquilante, 2008; Teixeira, 2006). Já na década de 70 , associou- se a promoção de saúde aos riscos comportamentais do indivíduo, os quais poderiam favorecer o adoecimento do indivíduo ou protegêlo desse adoecimento, inaugurando uma série de estudos sobre estilo de vida. Segundo Buss (2017), é importante diferenciar prevenção e promoção: a primeira orienta-se pela investigação sobre os fatores de risco e as causas do adoecimento na tentativa de identificá-los e controlá-los, evitando, desse modo, que o indivíduo adoeça. A promoção de saúde pode ser compreendida como estratégia que considera a necessidade de ações transversais para o cuidado à população. Essa perspectiva enfoca a diminuição de vulnerabilidades sociais para que as necessidades em saúde sejam atendidas com maior equidade, em defesa da qualidade de vida.

Ribeiro (2011) apresenta o contexto de mudanças sobre a visão de saúde-doença, que implica a passagem da primeira para a segunda revolução na saúde, na década de 70: "globalmente, pode afirmar-se que o desenvolvimento do modelo biomédico se centrou na doença, a primeira revolução da saúde se centrou na prevenção das doenças, e a segunda revolução da saúde se centrou na saúde” (p. 51). Trata-se da passagem de uma visão de saúde negativa para positiva. Essa positivação por meio dos cuidados primários em saúde ganhou destaque a partir da Conferência de Alma Ata (1978), com a defesa da criação de um sistema nacional de saúde nos diversos países, adaptado às realidades socioculturais, econômicas e políticas, de forma que as práticas em saúde estivessem ao alcance de toda a população.

Essa visão racionalizada e política impactou a realidade brasileira. No Brasil, a Reforma Sanitária, a Oitava Conferência Nacional de Saúde e o advento do SUS marcaram transformações importantes no cenário dos cuidados à saúde, promovendo certo deslocamento de práticas centradas no curativismo e no modelo biomédico em direção a práticas amparadas por compreensões sobre o processo saúde-doença que dialogam com a integralidade no cuidado, a intersetorialidade nas ações e a influência dos determinantes sociais (Westphal, 2012). O artigo 196 da Constituição Federal de 1988 (Brasil, 1988) enfatiza que a saúde é direito de todos e dever do Estado, garantido por meio de políticas sociais e econômicas, com dois objetivos: de reduzir o risco de doença e de outros agravos e de oferecer acesso universal e igualitário às ações e serviços para a promoção, proteção e recuperação. Por fim, Scliar
(2007) pontua que o artigo 196 da Constituição de 1988 constitui princípio que direciona o Sistema Nacional de Saúde (SUS) brasileiro, ainda que o SUS não discuta a conceituação de saúde.

Diante do exposto, é possível perceber que a Psicologia da Saúde se desenvolve de forma heterogênea e em muitos sentidos. Assim, nesta pesquisa, optamos pelo termo "Psicologia da Saúde", dado o percurso de sua constituição histórica elucidado na literatura. Destacamos, porém, que há duas outras terminologias na produção científica: "Psicologia e Saúde" e "Psicologia em contextos de saúde". Visto que nosso foco é a discussão sobre as contribuições da Fenomenologia para o desenvolvimento da Psicologia da Saúde, passamos a apresentar a Fenomenologia husserliana e seu método, além da influência deles para o movimento fenomenológico.

\section{Fenomenologia de Husserl}

A Fenomenologia tem sido utilizada como recurso de pesquisa em Psicologia da Saúde (Costa \& Castro, 2017; Gonçalves, Farinha \& Goto, 2016) e estudiosos discutem sobre o uso do método fenomenológico em pesquisas em Psicologia (Castro \& Gomes, 2011; Feijoo \& Goto, 2016; Giorgi, 2006; Giorgi, 2009; Goto, Costa \& Schievano, 2019) com predominância do modelo qualitativo advindo das ciências humanas. As pesquisas qualitativas são de grande relevância, pois levam em consideração a participação dos sujeitos na busca por significados.

De antemão, esclarecemos que a Fenomenologia compreende quatro significados. Primeiro, ela diz respeito ao movimento filosófico, cujo precursor foi Edmund Husserl (1859- 1938). Segundo, ela é uma filosofia rigorosa que se desenvolveu como um "movimento", por ter dinamismo e possuir um desenvolvimento que é "determinado por seus princípios intrínsecos, bem como pelas 'coisas' e, principalmente, porque se refaz como um fluxo, que compreende várias correntes paralelas que estão relacionadas, que não são homogêneas, e podem se mover em velocidades diferentes" (Spiegelberg, 1982, p. 2). O movimento fenomenológico teve como representantes discípulos de Husserl como: Edith Stein, Martin Heidegger, Emannuel Lévinas, entre outros. Terceiro, a Fenomenologia é um método de rigor no âmbito da Filosofia e da Psicologia Fenomenológica, que Husserl desenvolveu cientificamente. Por fim, esclarecemos que a Fenomenologia é uma teoria do conhecimento e método científico (ciência aqui tem o sentido do "saber racional" e não de ciência positivista), a diversas áreas do saber, não apenas no campo filosófico e/ou psicológico. Husserl desenvolveu a Fenomenologia como uma filosofia pura, começando pelas análises psicológicas, chegando às estruturas transcendentais. Fenomenologia Pura significa reflexão rigorosa de tudo aquilo que se mostra, isto é, 
os fenômenos, porém a partir das próprias coisas. $\mathrm{O}$ termo "fenômeno" em Husserl implica um conceito específico imprescindível para a compreensão do projeto da Fenomenologia. Fenômeno significa "aquilo que mostra; não somente aquilo que aparece ou parece" (Ales Bello, 2017, p. 17). Segundo a autora, "fenômeno" é aquilo que se manifesta a nós. Assim, a nós cabe o desafio de conhecer o significado do que se mostra na sua totalidade essencial, pois são as perguntas que interessam, não as respostas (Husserl, 1913/2006).

Husserl descreve rigorosamente os fenômenos à consciência, porque tudo aquilo que aparece ou manifesta, aparece a alguém, ou seja, o sujeito toma consciência de algo. Nesse sentido, a consciência é sempre ser consciente de alguma coisa, isto é, se caracteriza pelo que inicialmente F. Brentano chamou de "intencionalidade" (San Martín, 2008). No entanto, Husserl, superando o psicologismo e naturalismo de Brentano, mostra a intencionalidade como a forma de ser consciente $a$ priori, o que envolve a correlação sujeito-mundo. Nesse percurso, aprofunda, pela Filosofia e Psicologia Fenomenológica, a correlação intencional consciência- mundo, cuja "consciência surge, ora como consciência absoluta, ora, no correlato, como consciência psicológica, inserida agora no mundo natural [...]" (Husserl, 1913/2006, p. 166). Husserl chama essa condição originária de "a priori da correlação", um correlato que está presente no princípio de qualquer vivência, sendo que cada consciência, cada modo de ser consciente, têm seus objetos, e cada tipo de objeto tem seus modos peculiares de ser consciente. Todavia, será somente como Fenomenologia Transcendental que se poderá encontrar a via e a possibilidade de chegar ao fundamento das coisas: a própria subjetividade transcendental.

Castro e Gomes (2011) explicitam dois momentos distintos de apresentação do projeto da Fenomenologia. No primeiro, em "Investigações Lógicas” (1901/2007), a Fenomenologia é apresentada como um novo método descritivo que conduziria a uma ciência de fundação; no segundo, em "A ideia da Fenomenologia” (1907/2000), Husserl define a Fenomenologia Transcendental como uma filosofia científica rigorosa que, como consequência de sua aplicação, tornaria possível uma reforma metodológica em todas as outras ciências.

Para atingir seu objetivo, Husserl estabelece um método para garantir o rigor científico, pois tinha como finalidade encontrar um fundamento para todo e qualquer enunciado científico, ou seja, a sua generalidade essencial.

Não se pode confundir a generalidade irrestrita das leis naturais, como por exemplo, na lei 'todos os corpos são pesados', cuja proposição depende de uma 'posição de existência' (só os corpos efetivos são pesados); da generalidade eidética, cuja proposição 'todas as coisas materiais são extensas', por exemplo, mostra-se autenticamente universal (Husserl, 1913/2006, p. 41).

No intuito de alcançar a generalidade eidética, Husserl desenvolve um método capaz de oferecer uma condição de certeza, ou seja, o "método fenomenológico”, cujo princípio fundamental está na recondução de nossa reflexão às "coisas mesmas". O "voltar às coisas mesmas" (zu den Sachen selbst) significa, em termos gerais, que se deve dirigir a atenção, metodologicamente, aos fenômenos, a tudo aquilo que aparece imediatamente à consciência (Goto, 2015; Husserl, 1913/2006; San Martín, 2008).

Ales Bello (2006) explica que esse caminho metódico deve ser percorrido em etapas. Em primeiro lugar, Husserl mostra que o ser humano é capaz de compreender o sentido das coisas pela via da intuição, de pôr em perspectiva a essência, o sentido daquilo que se mostra. Segundo Husserl (1913/2006), toda intuição em que se dá algo originariamente é um fundamento de direito de conhecimento; tudo aquilo que se nos brinda deve ser tomado simplesmente como se dá, e somente dentro dos limites em que se dá. Para chegar ao sentido de algo, é preciso suspender (epoché), enquanto "pôr entre parênteses" a existência dos fatos, para compreender a essência (eidos) dos fenômenos, isto é, realizar reduções eidéticas para "purificar" os fenômenos, a fim de chegar à essência e separar o contingente. O segundo passo consiste na análise do sujeito que busca o sentido, por isso a importância da subjetividade. O sujeito é capaz de perceber as coisas e de refletir acerca delas, ou seja, tomar ciência dos atos da consciência.

Husserl busca, pelo método da redução, constituir uma Psicologia Pura através de uma consciência transcendental, distinguindo dois níveis: do sujeito psicológico (vivências empíricas) e do sujeito transcendental (vivências transcendentais). Assim define Husserl:

Ao mesmo tempo em que surgiu esta fenomenologia filosófica, mas sem distinguirse a princípio dela, surgiu uma nova disciplina psicológica paralela a ela quanto ao método e ao conteúdo: a psicologia a priori pura ou psicologia fenomenológica. Ao qual com afã reformador, pretende ser o fundamento metódico sobre o qual pode por princípio erguerse uma psicologia empírica cientificamente rigorosa. (Husserl, 2001, p. 223, citado por Goto, 2015, p. 171/2).

Essa Psicologia Pura foi denominada por Husserl de "Psicologia Fenomenológica", por ter como objeto a consciência e como método o fenomenológicoeidético. A "Psicologia Fenomenológica" fundase como uma ciência a priori e universal da 
subjetividade psíquica; busca descrever as vivências psíquicas intencionais e as suas estruturas sintéticas e universais; e, por fim, constitui-se como uma disciplina propedêutica à Fenomenologia Transcendental (Husserl, 1925/2001; Husserl, 1954/2012). Porém, Castro e Gomes (2011) alertam sobre o problema da transposição metodológica da Fenomenologia Filosófica para a Psicologia. Por fim, Feijoo e Goto (2016) advertem que há confusões acerca da concepção de "Psicologia Fenomenológica" na Psicologia brasileira.

Um modelo metodológico tradicional na Psicologia proposto por Amedeo Giorgi passou a ser muito utilizado no Brasil. Giorgi (2006) enfatiza a importância da fidelidade aos princípios filosóficos também quando aplicados na Psicologia e nas ciências humanas. Para ele, três procedimentos metodológicos são imprescindíveis ao se utilizar o método fenomenológico na pesquisa empírica em Psicologia: primeiro, suspender todo e qualquer posicionamento ontológico-epistemológico (epoché); segundo, focalizar o fenômeno encontrado; terceiro, a partir da variação livre da imaginação, reconduzir tal fenômeno ao âmbito intencional e, desse modo, alcançar sua essência (sentido), descrevendo-se todo esse processo. Logo, por esse caminho de investigação, seria possível sair da experiência dos fatos e alcançar o fundamento eidético dos fenômenos.

Feijoo e Goto (2016) e Goto, Costa e Schievano (2019) sustentam que a investigação deve sair do empírico (fatos) para o fenomenológico (eidético), ou seja, a descrição das vivências psíquicas, sendo essa via chamada atitude antinatural (Husserl, 1901/2007). Esses autores adotam um posicionamento crítico sobre a proposta da aplicação do método em pesquisas qualitativas adotado por Amedeo Giorgi pelo desenvolvimento de uma Psicologia empírico-fenomenológica. Evidenciam que a proposta de Giorgi é, em verdade, uma pesquisa mais hermenêutica do que uma Psicologia Fenomenológica das vivências psíquicas. Por isso, defendem o método fenomenológico husserliano a partir da redução psicológico-eidética nas pesquisas em Psicologia tal como o projeto original husserliano.

Dado o exposto, afirmamos de pronto que a literatura apresenta divergências tanto sobre o campo da Psicologia da Saúde quanto da Fenomenologia, cujo método tem sido empregado especialmente em pesquisas qualitativas em Psicologia. Este estudo propôs uma reflexão crítica sobre o conhecimento produzido a partir do diálogo entre Fenomenologia e Psicologia da Saúde, investigando as contribuições daquela para o processo saúde-doença- cuidado. Além disso, buscamos conhecer a produção acadêmica brasileira sobre a interface Saúde e Fenomenologia em Psicologia, com a inclusão das leituras fenomenológicas bem como da perspectiva humanista-existencial.

\section{Método}

Realizamos uma revisão integrativa em três bases de dados: SciELO (Scientific Eletronic Library Online), PePSIC (Periódicos Eletrônicos em Psicologia) e LILACS (Literatura Latino-Americana e do Caribe em Ciências da Saúde). Utilizamos, inicialmente, os descritores "fenomenologia" e "saúde", a fim de conhecermos a produção geral no Brasil. Em sequência, testamos outros indexadores em cada uma das bases, a saber: "fenomenologia" e "psicologia da saúde"; "psicologia fenomenológica" e "saúde"; "psicologia fenomenológico- existencial" e "saúde”. Foram encontrados 247 artigos, sendo 160 artigos na base de dados SciELO; 51 na PePSIC; e 36 na LILACS (Tabela 1).

Após a busca que reuniu os 247 artigos, lemos todos os resumos. Nos casos em que a leitura do resumo foi insuficiente, acessamos a versão integral para confirmação de elegibilidade e inclusão no estudo. A maioria dos artigos excluídos ( $\mathrm{n}=103)$, pela leitura dos resumos, apresentava o tema de saúde com algum uso teórico e/ou metodológico de alguma base fenomenológica, porém em outro campo das ciências da saúde, com primazia à enfermagem. Outros 26 artigos foram eliminados por repetição. Também foram excluídos dois artigos de revisão e uma resenha. E, por fim, 68 artigos que não respondiam à questão central da pesquisa também foram excluídos, porque, apesar de abordarem a correlação fenomenologia e saúde, tratavam de dois sub-temas: equipes de saúde multiprofissionais e a área de saúde em toda sua abrangência, sem escopo no campo da psicologia.

Posterior à leitura de resumo e dos casos em que foi preciso ler a versão integral para apreciar a elegibilidade, para averiguar se o artigo científico contemplava a relação entre fenomenologia e saúde, realizamos a análise de inclusão quanto ao tema em psicologia brasileira. Foram lidos na íntegra 47 artigos, sendo 29 artigos (SciELO); 15 artigos (PePSIC); três artigos (LILACS). Destes foram excluídos, predominantemente, mais 29, cujo tema principal era concernente apenas à psicopatologia. Dos 18 artigos, restou a dúvida quanto à inclusão de sete. Nesse caso, um segundo leitor, autor deste artigo, analisou-os na íntegra, para esclarecer quanto à inclusão ou não da produção científica. Finalmente, obtivemos 13 artigos selecionados por ir ao encontro da pergunta central de nossa pesquisa (Tabela 1).

Os artigos recuperados foram analisados a partir de duas categorias: (1) Fenomenologia e (2) Psicologia da Saúde. Na categoria (1), discutimos como a Fenomenologia foi empregada em cada artigo selecionado. Já na categoria (2), discutimos a atuação do psicólogo em serviços de saúde e quais modelos ele emprega para uma visão de Psicologia da Saúde. 
Tabela 1

Apresentação de Artigos Selecionados, Eliminados e Recuperados em cada Base de Dados

\begin{tabular}{cccccc}
\hline $\begin{array}{c}\text { Bases de } \\
\text { Dados }\end{array}$ & $\begin{array}{c}\text { Número de } \\
\text { artigos } \\
\text { Localizados }\end{array}$ & $\begin{array}{c}\text { Eliminados } \\
\text { por repetição }\end{array}$ & $\begin{array}{c}\text { Eliminados } \\
\text { por critériosde } \\
\text { exclusão }\end{array}$ & $\begin{array}{c}\text { Eliminados } \\
\text { após leiturado } \\
\text { resumo }\end{array}$ & $\begin{array}{c}\text { Recuperados } \\
\text { leitura naÍntegra }\end{array}$ \\
\hline SCIELO & 160 & 20 & 134 & 134 & 6 \\
PEPSIC & 51 & 05 & 39 & 39 & 7 \\
LILACS & 36 & 01 & 35 & 35 & 0 \\
\hline TOTAL & 247 & 26 & 208 & 208 & $\mathbf{1 3}$ \\
\hline
\end{tabular}

\section{Resultados e Discussão}

Os artigos recuperados foram publicados entre 2010 e 2018, apesar de a busca ter sido realizada a partir do ano 2000 (ver Tabela 2). Notamos que as pesquisas dessa década utilizaram da Fenomenologia para produzir conhecimento em Psicologia da Saúde. Ademais, o conhecimento produzido na área pelas contribuições da Fenomenologia carece de desenvolvimento gradual e se mostra recente e promissor. Nessa direção, o aumento de publicações recentes parece focalizar a produção de saúde a partir da compreensão de significado pelos sujeitos (usuários de serviços de saúde e profissionais de saúde) envolvidos no processo saúde-doençacuidado.

Entre a diversidade de periódicos, observamos indício de alguma prevalência sobre a temática relativa às pesquisas em Fenomenologia. Tratase do periódico Revista da Abordagem Gestáltica, onde foram encontrados quatro artigos (ver Tabela 2). Quanto à autoria, também existe diversidade. Chamam atenção produções de autoria ou coautoria entre docentes e discentes, ou seja, a produção de conhecimento no processo formativo acadêmico, além da parceria entre profissionais de Psicologia e da Filosofia. Nesse cenário, Márcio Luís Costa, filósofo e pesquisador da pós-graduação em Psicologia da Universidade Católica Bom Bosco em Campo Grande, assina três artigos (ver Tabela 2).

As pesquisas são todas de cunho qualitativo. Tanto a atuação do psicólogo nos campos de saúde bem como o uso da Fenomenologia na pesquisa apresentam-se de forma heterogênea. Consideramos essa pluralidade como riqueza, dada a busca pelos significados subjetivos.

Portanto, predomina o conhecimento sobre a produção de sentido pelos sujeitos afetados perante os fenômenos de saúde-doença-cuidado em distintos contextos. A Tabela na página seguinte (Tabela 2) mostra com clareza essa heterogeneidade.

\section{Fenomenologia}

Vendruscolo (2012) busca uma forma de compreender e fazer Psicologia da Saúde pela Psicologia Fenomenológico-existencial enquanto visão antropológica pela qual os sujeitos podem significar as suas vivências e se responsabilizarem por suas escolhas. Gonçalves, Farinha e Goto (2016) destacam que psicólogos que se vinculam à fenomenologia-existencial compreendem o ser humano em sua totalidade como um ser em relação com o mundo, com os outros e consigo mesmo. Amaral, Avelar e Santos (2018) identificam seu estudo numa perspectiva fenomenológicoexistencial segundo Heidegger, o qual define fenômeno como "o que se revela, que se faz ver ou que vem à luz” (p. 6). Recordamos que fenômeno, um dos principais conceitos da Fenomenologia, foi cunhado por Husserl, logo se trata de apropriação de Heidegger. O método usado, citado pelos autores, foi de análise de sentido (Critelli, 1996), composto por desvelamento (afetabilidade); revelação (aparecimento); testemunho (comunicabilidade); veracização (outros olhares); e autenticação (publicização).

Em Amaral, Avelar e Santos (2018); Gonçalves, Farinha e Goto (2016) e Vendrusculo (2012), a Fenomenologia se mostra correlacionada ao existencial, sendo Husserl o precursor daquela e Heidegger um expoente deste. Esse uso em psicologia implica uma abordagem, ou seja, "compreensão e visão de mundo” (Feijoo \& Mattar, 2014, p. 447). Ademais, para Feijoo e Mattar (2014), as perspectivas fenomenológico-existenciais em psicologia, ao investigar temas vivenciais ou existenciais, constituem em atos na cooriginariedade homemmundo.

Almeida, Rezende, Schall e Modena (2010) estudam os sentidos da corporeidade pela referência à Fenomenologia do corpo de Heidegger em duplo sentido: ao poder-ser (potência) e à limitação (indigência). Almeida et al. (2010) elucidam a corporeidade: "ser-corpo é constituinte do existir, sendo a corporeidade um caráter fundamental do homem, inseparável dele e integrante de suas relações com o mundo” (p. 762). O método para a análise de dados, citado pelos autores, segue o modelo de Feijoo (1999), pela construção de categorias para análise dos significados presentes nos discursos dos sujeitos pesquisados. Matar et al. (2016) valem da daseinanálise de Heidegger e Boss para pensar o adoecimento sem dualismo entre corpo e psiquismo. A corporeidade é uma das esferas do ser do homem, por meio da qual se atualiza a existência 
Tabela 2

Caracterização dos Artigos Recuperados

\begin{tabular}{|c|c|c|c|c|}
\hline Título do artigo & Autores & Periódico & Psicologia em contextos desaúde & Fenomenologia \\
\hline $\begin{array}{l}\text { Atendimento psicológico } \\
\text { eminstituições: da } \\
\text { tradição à } \\
\text { existencial }\end{array}$ & (2012) & $\begin{array}{c}\text { Estudos e } \\
\text { Pesquisas em } \\
\text { Psicologia. (Rio } \\
\text { de Janeiro) }\end{array}$ & $\begin{array}{c}\text { Atendimento Psicológico } \\
\text { Fenomenológico-Existencial em } \\
\text { instituição de saúde: clínica- escola } \\
\text { / UNAERP. Estudo de caso } \\
\text { qualitativo. }\end{array}$ & $\begin{array}{c}\text { Psicologia } \\
\text { fenomenológica- } \\
\text { existencial. }\end{array}$ \\
\hline $\begin{array}{l}\text { Os sentido da } \\
\text { corporeidade em } \\
\text { ostomizados porcâncer }\end{array}$ & $\begin{array}{c}\text { Almeida, } \\
\text { Rezende, } \\
\text { Schalle \& } \\
\text { Modena }(2010)\end{array}$ & $\begin{array}{l}\text { Psicologia em } \\
\text { Estudo (Maringá) }\end{array}$ & $\begin{array}{l}\text { Hospital oncológico em Belo } \\
\text { Horizonte, MG. Significados } \\
\text { vivenciais do adoecimento, uso de } \\
\text { bolsa de colostomia e cuidado. } \\
\text { Pesquisa qualitativa. }\end{array}$ & $\begin{array}{l}\text { Fenomenologia } \\
\text { hermenêutica de } \\
\text { Heidegger.Análise } \\
\text { fenomenológica } \\
\text { (Feijoo, 1999). }\end{array}$ \\
\hline $\begin{array}{l}\text { Da tradição em } \\
\text { Psicossomática às } \\
\text { Considerações da } \\
\text { Daseinsanálise }\end{array}$ & $\begin{array}{l}\text { Matar et al. } \\
\text { (2016) }\end{array}$ & $\begin{array}{l}\text { Psicologia: } \\
\text { Ciência e } \\
\text { Profissão }\end{array}$ & $\begin{array}{l}\text { Estudo teórico sobre os } \\
\text { fundamentos para a prática do } \\
\text { cuidado psicológico em saúde. }\end{array}$ & $\begin{array}{l}\text { Fenomenologia } \\
\text { hermenêutica de } \\
\text { Heidegger e } \\
\text { Daseinsanalyse de } \\
\text { Boss. }\end{array}$ \\
\hline $\begin{array}{l}\text { A experiência } \\
\text { fenomenológica e o } \\
\text { trabalho em grupo na } \\
\text { saúde mental }\end{array}$ & $\begin{array}{c}\text { Rocha \& } \\
\text { Cardoso(2017) }\end{array}$ & $\begin{array}{l}\text { Psicologia \& } \\
\text { Sociedade }\end{array}$ & $\begin{array}{l}\text { Grupo de saúde mental nomeado } \\
\text { como Grupo Comunitário de Saúde } \\
\text { Mental (GCSM), significado do } \\
\text { vivido na perspectiva dos } \\
\text { participantes. } \\
\text { Pesquisa qualitativa. }\end{array}$ & $\begin{array}{l}\text { Fenomenologia de } \\
\text { Husserl. }\end{array}$ \\
\hline $\begin{array}{l}\text { Contribuições da } \\
\text { fenomenologia de Edith } \\
\text { Stein para a atuação do } \\
\text { psicólogonos Núcleos } \\
\text { deApoioà Saúde da } \\
\text { Família }\end{array}$ & $\begin{array}{c}\text { Silva \& } \\
\text { Cardoso(2013) }\end{array}$ & $\begin{array}{c}\text { Revista } \\
\text { Latinoamericana } \\
\text { de Psicopatologia } \\
\text { Fundamental }\end{array}$ & $\begin{array}{l}\text { Estudo teórico sobre a atuação do } \\
\text { psicólogo nos Núcleos de Apoioà } \\
\text { a Estratégia Saúde da Família. }\end{array}$ & $\begin{array}{l}\text { Fenomenologia de } \\
\text { Edith Stein. }\end{array}$ \\
\hline $\begin{array}{l}\text { A fenomenologia e a } \\
\text { pesquisa em psicologiada } \\
\text { saúde }\end{array}$ & $\begin{array}{l}\text { Costa \& Castro } \\
\quad(2017)\end{array}$ & $\begin{array}{l}\text { Rev. Nufen: } \\
\text { Phenom. Interd } \\
\text { (Belém) }\end{array}$ & $\begin{array}{l}\text { Estudo teórico sobre o diálogoentre } \\
\text { a Fenomenologia e a Psicologia da } \\
\text { Saúde. }\end{array}$ & $\begin{array}{l}\text { e Fenomenologia de } \\
\text { Husserl, Heidegger } \\
\text { eLévinas. }\end{array}$ \\
\hline $\begin{array}{l}\text { Mulheres Transplantadas } \\
\text { Renais: um Olhar } \\
\text { Fenomenológico } \\
\text { Existencial para a } \\
\text { Experiência da Gestação }\end{array}$ & $\begin{array}{l}\text { Amaral, Avelar } \\
\text { \& Santos } \\
\text { (2018) }\end{array}$ & $\begin{array}{l}\text { Revista da } \\
\text { Abordagem } \\
\text { Gestáltica }\end{array}$ & $\begin{array}{c}\text { Pesquisa qualitativa. } \\
\text { Compreender como as mulheres } \\
\text { transplantadas renais experienciam } \\
\text { a gestação. } \\
\text { Importância da intervenção } \\
\text { psicológica à gestante } \\
\text { transplantada renal e suafamília. }\end{array}$ & $\begin{array}{c}\text { Psicologia } \\
\text { Existencial. } \\
\text { Método da } \\
\text { Analítica de Sentido } \\
\text { (Critelli,1996). }\end{array}$ \\
\hline $\begin{array}{l}\text { Experiência da Primeira } \\
\text { Sessão deHemodiálise: } \\
\text { UmaInvestigação } \\
\text { Fenomenológica }\end{array}$ & $\begin{array}{l}\text { Brito et al. } \\
\text { (2017) }\end{array}$ & $\begin{array}{l}\text { Revista da } \\
\text { Abordagem } \\
\text { Gestáltica }\end{array}$ & $\begin{array}{l}\text { Estudo de caso. Significados e } \\
\text { suporte psicológicos na experiência } \\
\text { da primeira sessão dehemodiálise } \\
\text { de paciente renal crônico no } \\
\text { Hospital das Clínicas de } \\
\text { Pernambuco. }\end{array}$ & $\begin{array}{c}\text { Método } \\
\text { Fenomenológico de } \\
\text { Investigação em } \\
\text { Psicologia (Giorgi } \\
\text { \& Souza, 2010). }\end{array}$ \\
\hline A Invenção doSujeito & $\begin{array}{l}\text { Castro \& Costa } \\
\quad(2018)\end{array}$ & $\begin{array}{l}\text { Psicologia: } \\
\text { Ciência e } \\
\text { Profissão }\end{array}$ & $\begin{array}{l}\text { Estudo teórico sobre o paradigma } \\
\text { do sujeito logico e do sujeito } \\
\text { ontológico na modernidade e sua } \\
\text { relação com pesquisa em } \\
\text { Psicologia da Saúde. }\end{array}$ & $\begin{array}{l}\text { Fenomenologia de } \\
\text { Husserl. }\end{array}$ \\
\hline $\begin{array}{l}\text { Plantão psicológico em } \\
\text { Unidade Básica de } \\
\text { Saúde: Atendimento em } \\
\text { Abordagem Humanista- } \\
\text { fenomenológica }\end{array}$ & $\begin{array}{l}\text { Gonçalves, } \\
\text { Farinha \& } \\
\text { Goto }(2016)\end{array}$ & $\begin{array}{l}\text { Revista da } \\
\text { Abordagem } \\
\text { Gestáltica }\end{array}$ & $\begin{array}{l}\text { Estudo qualitativo- } \\
\text { fenomenológico. Buscou descrever } \\
\text { atendimentos psicológicos no } \\
\text { formato PlantãoPsicológico } \\
\text { realizados em uma Unidade Básica } \\
\text { de Saúde (UBS)no interior de } \\
\text { Goiás para prevenção e promoção } \\
\text { de saúde. }\end{array}$ & $\begin{array}{l}\text { Psicologia } \\
\text { Humanista- } \\
\text { Existencial }\end{array}$ \\
\hline $\begin{array}{l}\text { Psicologia e Saúde } \\
\text { Pública: Cartografi a das } \\
\text { Modalidades de Prática } \\
\text { Psicológica nas } \\
\text { Policlínicas }\end{array}$ & $\begin{array}{c}\text { Cimino \& } \\
\text { Leite (2016) }\end{array}$ & $\begin{array}{l}\text { Revista } \\
\text { Psicologia e } \\
\text { Saúde }\end{array}$ & $\begin{array}{l}\text { Estudo qualitativo. Buscou } \\
\text { cartografar a prática dos psicólogos } \\
\text { nas PoliclínicasMunicipais do } \\
\text { Recife. }\end{array}$ & $\begin{array}{l}\text { Fenomenologia de } \\
\text { Husserl. Método } \\
\text { Fenomenológico de } \\
\text { Investigação em } \\
\text { Psicologia (Giorgi, } \\
\text { 2008). }\end{array}$ \\
\hline $\begin{array}{l}\text { "Duas Faces da Mesma } \\
\text { Moeda": Vivência dos } \\
\text { Psicólogos que Atuamna } \\
\text { Rede de Atenção } \\
\text { Psicossocial }\end{array}$ & $\begin{array}{c}\text { Muhl \& } \\
\text { Holanda(2016) }\end{array}$ & $\begin{array}{l}\text { Revista da } \\
\text { Abordagem } \\
\text { Gestáltica }\end{array}$ & $\begin{array}{l}\text { Estudo qualitativo. Compreenderas } \\
\text { vivências dos psicólogos que } \\
\text { atuam em saúde mental pública } \\
\text { têm no cotidiano do seu serviço na } \\
\text { Rede de Atenção Psicossocialno } \\
\text { Litoral do Paraná. }\end{array}$ & $\begin{array}{l}\text { Fenomenologia de } \\
\text { Husserl e Dilthey. } \\
\text { Método } \\
\text { Fenomenológico } \\
\text { (Gomes, 1997). }\end{array}$ \\
\hline $\begin{array}{l}\text { Produção de Saúde } \\
\text { como Afirmação deVida }\end{array}$ & $\begin{array}{l}\text { Costa \& } \\
\text { Bernardes } \\
(2012)\end{array}$ & $\begin{array}{l}\text { Saúde Soc. São } \\
\text { Paulo }\end{array}$ & $\begin{array}{l}\text { Estudo teórico. Discute o conceito } \\
\text { de saúde e doença, pela produção } \\
\text { de alteridade e vida, através da } \\
\text { Psicologia Social, como forma de } \\
\text { contribuir para o debate e } \\
\text { implementação doSUS. }\end{array}$ & $\begin{array}{l}\text { Fenomenologia de } \\
\text { Lévinas. }\end{array}$ \\
\hline
\end{tabular}


humana, o dasein (ser-aí). Trata-se, pois, de rever a compreensão sobre a dicotomia presente na tradição psicossomática, para se pensar o cuidado psicológico em saúde a partir do referencial da Fenomenologia hermenêutica de Heidegger e Boss.

Almeida, Rezende, Schall e Modena (2010) e Matar et al. (2016) desenvolveram uma Fenomenologia do corpo com referência principal em Heidegger. Este investigou o dasein (ser- aí) ao abandonar a referência à consciência e radicalizar a noção de intencionalidade. Dito de outra forma, Heiddeger investiga o sentido de ser, no caso sercorpo, de modo fenomenológico (Feijoo \& Mattar, 2014). Dessa maneira, a Fenomenologia hermenêutica de Heidegger contribui para a analítica do ser-corpo em fenômenos de saúde.

Silva e Cardoso (2013) se valem da antropologia fenomenológica de Edith Stein, estudiosa de Husserl, para reflexão sobre a Psicologia da Saúde. Segundo as autoras, ao citar Ales Bello (2007), "Stein visa escavar o interno do ser humano” (p. 248). Pela visão da empatia em Stein, o estudo aponta dois sentidos de uma atitude humanizada: "no reconhecimento da dor enquanto uma experiência humana comum a todos e na limitação real do ser humano diante da possibilidade de resolução dos sofrimentos" (p. 253, grifo da autora). Stein contribui também pela visão de comunidade entendida não como pessoas reunidas, mas como responsabilidade, solidariedade, cuidado e afeto, aponta o estudo.

Goto e Moraes (2016) sublinham a concepção de Stein sobre a Fenomenologia: ciência rigorosa que busca alcançar a essência dos fenômenos através do método fenomenológico. Acrescentam uma peculiaridade da fenomenologia de Stein: “... buscou ir além de seu mestre e desenvolveu uma Fenomenologia de cunho mais realista" (p. 65). Nesse sentido, a fenomenologia de Stein oferece valiosas contribuições nos contextos de saúde pelos estudos da empatia e da comunidade em busca da essência do humano.

Costa e Bernardes (2012) discutem a saúde articulada à Psicologia Social pelas contribuições da Fenomenologia de Emanuel Lévinas. Este reflete sobre o fenômeno da alteridade de forma ética, o que implica uma visão antropológica não restrita ao individual, mas implicada ao apelo responsável às diferenças, no caso em termos de saúde coletiva. Grzibowski (2016) apresenta Lévinas como estudioso de Husserl para desenvolver uma Fenomenologia da subjetividade encarnada. Lévinas também foi influenciado por Heidegger, porém discorda deste em relação à busca pelo sentido. Para Lévinas, o outro se mostra na diferença ao apelar por respeito, ou seja, o centro do pensamento levinasiano é ético e não ontológico, como propôs Heidegger. Daí, Lévinas contribui em Fenomenologia através do pensar o fenômeno da alteridade essencialmente ética, cuja visão favorece o campo da saúde.
Rocha e Cardoso (2017) utilizam a epistemologia fenomenológica para fundamentar a pesquisa acerca do grupo em saúde mental, especialmente o conceito de experiência vivida em Husserl, para o qual se estabelece relação de sentido entre sujeitos e mundo. Pela experiência vivida, é possível compreender como os sujeitos significam seus cotidianos. Este estudo também usou Fenomenologia husserliana como método. Acerca disso, Rocha e Cardoso (2017) comentam que a singularidade da aplicação do método fenomenológico husserliano à pesquisa empírica é alvo de aprimoramentos, contudo não se trata da objetivação da subjetividade e nem de singularizar cada sujeito. Afirmam os autores que se trata da busca dos traços comuns da experiência vivida no recorte espaço-temporal do fenômeno estudado.

Costa e Castro (2017) frisam que a pesquisa em Psicologia da Saúde à luz do método fenomenológico apenas pode existir a partir do horizonte do vivido pelos participantes e pelo pesquisador. Outra questão diz respeito à interação entre pesquisador e pesquisado: "há uma pesquisa, um pesquisador e um problema de pesquisa, porque existem seres humanos, que estão estabelecidos no mundo por meio de uma interação intencional e co-presente, cuja finalidade é o conhecimento” (p. 135). Já Brito et al. (2017) enfatizam o uso do método fenomenológico por possibilitar compreender como o sujeito descreve a sua experiência. O método fenomenológico de investigação em Psicologia (Giorgi \& Souza, 2010) foi utilizado para análise dos dados. Castro e Costa (2018) adotam a Fenomenologia de Husserl como fundamento teórico para a reflexão sobre a subjetividade humana e valem do método fenomenológico em busca da unidade de sentido essencial sem dualismos, pré-juízos, sem se prenderem ao lógico e ao subjetivismo. Por sua vez, Cimino e Leite (2016) empregam o método fenomenológico para interpretação das vivências, proposto por Giorgi (2009), constituído de quatro passos: sentido do todo, identificação de unidades de significado, transposição da linguagem dos sujeitos em linguagem psicológica, síntese de unidades de significado.

Em específico, Muhl e Holanda (2016) partem do conceito de vivência de acordo com a perspectiva fenomenológica concebida por Edmund Husserl e Wilhelm Dilthey para compreender a experiência vivida por psicólogos na Rede de Atenção Psicossocial. Os autores especificam a importância do concceito: "A vivência é o elo de ligação entre o geral e o individual, entre o universal e o singular, entre o objetivo e o subjetivo." (Muhl \& Holanda, 2016, p. 60). No âmbito das ciências humanas, o estudo utilizou o método fenomenológico para descrever as vivências e compreender seus significados. $\mathrm{O}$ percurso metodológico, citado pelos autores, seguiu as etapas propostas por Gomes (1997): 1) descrição 
fenomenológica (vivência dos psicólogos a partir de dados empíricos), 2) redução fenomenológica (unidades compreensivas de sentido) e 3) interpretação fenomenológica (essência do objeto estudado). Dessa forma é que a Fenomenologia contribui para se entender o vivencial da atuação dos psicólogos na saúde mental pública.

Entre os percursos metodológicos elucidados, constatamos a referência ao método fenomenológico de Husserl transposto à Psicologia com tendência ao uso do modelo proposto por Amedeo Giorgi (Giorgi, 2006; Giorgi, 2009; Giorgi \& Souza, 2010). Acerca dessa discussão, vamos ao encontro da posição de Feijoo e Goto (2016), que defendem a fidelidade à concepção teórica e metodológica em todos os seus elementos e momentos fundamentais, proposta por Husserl para uma Psicologia Fenomenológica. Para os autores, não se trata de adaptação técnica da teoria e do método fenomenológicos, como defendem Giorgi (2006) e Giorgi e Sousa (2010), pois, desse modo, haveria sempre o risco de abalar a ordem estrutural da investigação fenomenológica husserliana. (Feijoo \& Goto, 2016, p. 7).

A Fenomenologia contribui para a Psicologia da Saúde, pelos artigos selecionados e discutidos, com predomínio da compreensão das experiências vividas pelos sujeitos, o que se alinha à perspectiva da Psicologia Fenomenológica proposta por Husserl. $\mathrm{O}$ foco na subjetividade psíquica para descrever os significados dos fenômenos ligados à Saúde predomina nas pesquisas encontradas (Brito et al., 2017; Castro \& Costa, 2018; Cimino \& Leite, 2016; Costa \& Castro, 2017; Muhl \& Holanda, 2016; Rocha \& Cardoso, 2017). Ante o exposto, uma Psicologia Fenomenológica favorece o desenvolvimento de pesquisas no campo de Saúde, para se entender o sentido conferido pelos sujeitos às suas vivências no âmbito do processo saúde-doença-cuidado. Há carência de pesquisas fenomenológicas em Psicologia da Saúde que sejam fiéis à base teórica e metodológica husserliana, posição que defendemos neste artigo.

Por fim, outras leituras fenomenológicas contribuem para o campo de Saúde no curso da Psicologia através da reflexão acerca de fenômenos do humano, como a empatia e comunidade em E. Stein (Silva \& Cardoso, 2013); a corporeidade na analítica do dasein em M. Heidegger (Almeida, Rezende, Schall \& Modena, 2010; Matar et al., 2016); e a alteridade ética em E. Lévinas (Costa \& Bernardes, 2012). A influência da Fenomenologia de Husserl no pensamento de outros filósofos tidos como fenomenólogos e existencialistas está para além dos achados, logo outras pesquisas se fazem necessárias para o avanço do campo nessa perspectiva.

\section{Psicologia da Saúde \\ Neste tópico apresentamos as compreensões sobre o processo saúde-doença nos artigos}

recuperados e o papel do psicólogo nos contextos pesquisados. Com relação ao primeiro aspecto, chama atenção a relevância dada à alteridade do sujeito nas práticas de saúde que servem à produção de vida (Costa \& Bernardes, 2012; Costa \& Castro, 2017; Silva \& Cardoso, 2013). Esses autores recorrem ao mundo em que as relações são construídas pela diversidade de vivências e, dessa forma, buscam conceber a singularidade de forma integral e a alteridade que permeia os humanos.

Costa e Bernardes (2012) defendem a possibilidade de pensar a alteridade no campo da saúde como saída da visão apenas técnica para uma compreensão ética e política: "no marco da afirmação da vida, a diferença que gera diferença pode ser pensada como alteridade. As condições estratégicas para a produção de vida e saúde somente podem ser pensadas do âmbito da alteridade" (p. 832). Silva e Cardoso (2013) desenvolveram um estudo com o intuito de fundamentar ações centradas na potencialidade do desenvolvimento humano e na alteridade, em vez de centrar na doença e no individualismo, de modo a não discriminar pessoas em sofrimento psíquico no campo da saúde mental na atenção primária. Considerar a alteridade no processo saúde-doença-cuidado implica reconhecer um movimento de vida singular no âmbito corporal, psíquico e espiritual (Silva \& Cardoso, 2013).

Vendruscolo (2012) aponta que, em Psicologia da Saúde, a doença surge como algo inesperado aos sujeitos, os quais vão lhe atribuir um sentido, dentro de suas possibilidades e limites. Almeida, Rezende, Schall e Modena (2010) buscam compreender como os sujeitos vivem a nova condição existencial perante o tratamento da doença. Nesse sentido, Matar et al. (2016) consideram que o adoecer afeta a unidade indivisível da existência na relação com o mundo através da corporeidade. Rocha e Cardoso (2017), por sua vez, pesquisaram o potencial terapêutico da experiênciavivida em uma prática em grupo de promoção à saúde mental numa visão biopsicossocial. Os participantes, usuários, familiares e profissionais relataram o trabalho como um espaço de busca do "sentido da vida" pelas experiências vividas em detrimento da doença e o saber sobre ela. O grupo focado no significado do vivido implicou reconhecimento do humano. Desse modo, os estudos apontaram para a importância das experiências vividas, singular e coletivamente, e seus sentidos para o lidar com o processo de saúdedoença e produção de cuidados.

Um segundo aspecto destacável se relaciona ao papel do psicólogo nas instituições e equipes de saúde. Ele aparece como promotor de diálogo entre especialidades, aberto ao outro e a críticos sobre os valores que perpassam as definições de saúde ampliada (Silva \& Cardoso, 2013). Para Vendrusculo (2012), o papel do psicólogo, em equipe de saúde ou não, deve ser de atenção à pessoa que adoece e não à doença em si. O diferencial dele no atendimento 
em instituições na área de saúde, conclui a pesquisa, está na maneira como o psicólogo compreende a si, ao outro e ao processo de ajuda, para além dos aspectos técnicos. O profissional pode refugiarse na técnica quando não consegue lidar com sua condição existencial na relação com o paciente. Já Brito et al. (2017) defendem que o papel do psicólogo é fundamental para melhorar a adesão ao tratamento. Almeida et al. (2010) concluem que o apoio psicológico implica o cuidado de si, do outro e da saúde e tem como finalidade "ressignificação da situação, pois esse profissional busca junto com o doente o sentido de sua existência” (p. 767). Gonçalves, Farinha e Goto (2016) destacam que o trabalho do psicólogo é desafiado por um modo dinâmico de fazer saúde, o que implica a substituição do paradigma da clínica pelo da saúde pública. A empatia do psicólogo oferece condições para ele "cuidar das pessoas de forma integral" (p. 231), as quais serão compreendidas como em enfrentamento de adversidades à saúde ativamente.

Algumas pesquisas enfatizam o campo da Psicologia da Saúde (Castro \& Costa, 2018; Costa \& Castro, 2017; Vendrusculo, 2012), porém a maioria dos estudos discute os fenômenos de saúde a partir da relação saúde-doença-cuidado sem explicitar a denominação em Psicologia. Predomina a visão do modelo biopsicossocial em todas as pesquisas. A compreensão de saúde- doença não se restringe ao olhar sobre a doença e o tratamento, mas atenta à produção de saúde.

Nesse caso, numa visão de saúde coletiva, saúde se atrela à alteridade como promoção da vida e não se reduz à objetivação tecnicista (Costa \& Bernardes, 2012, Costa \& Castro, 2017, Matar et., 2016; Silva \& Cardoso, 2013). Também é unânime a defesa da visão de ser humano concreto, social, corporal, afetivo, espiritual, constituído historicamente pelas relações, a exemplo de Brito et al. (2017), Costa e Castro (2018) e Gonçalves, Farinha e Goto (2016), que enfatizam essa complexidade multidimensional.

O "olhar" da Psicologia da Saúde sobre os usuários dos serviços de saúde se direciona à compreensão dos significados das experiências vividas pelos sujeitos frente aos fenômenos envolvidos no processo saúde-doença-cuidado (Almeida, Rezende, Schall \& Modena, 2010; Amaral, Avelar \& Santos, 2018; Brito et al., 2017; Castro \& Costa, 2018; Gonçalves, Farinha \& Goto, 2016; Rocha \& Cardoso, 2017). Essa visão é integrativa, porque não dissocia sujeito e mundo, sujeito e família/ sociedade. Além disso, a principal contribuição do "olhar" fenomenológico sobre o campo é a compreensão vivencial dos fenômenos em saúde pela produção (inter) subjetiva psíquica. Na atuação do psicólogo em Saúde, é nuclear que ele se forme continuamente com essa visão de sujeito (usuário) e de processo saúde-doença-cuidado pela singularidade e pela diversidade.
Castro e Costa (2018) discutem o conceito entre sujeito lógico e sujeito ontológico, com a finalidade última de pensar as contribuições da Psicologia da Saúde no tocante ao papel dos sujeitos nas pesquisas desse campo. Eles discutem que o modelo científico formal desconsidera os sujeitos participantes da pesquisa. Já o modelo subjetivo, ao considerar o sujeito concreto e singular, afirma e promove a vida. Nessa perspectiva, as pesquisas ganham novas ferramentas teóricas para discussão acerca de temas como: relação entre modelo produtivista e qualidade de vida dos pesquisadores; a saúde entendida para além do modelo biomédico, ou seja, biopsicossocialmente; e relação entre qualidade de pesquisa e comprometimento ético.

Três elementos específicos se destacam nos resultados encontrados quanto à atuação do psicólogo em contextos de saúde: (1) a religiosidade como um elemento importante para o cuidado em saúde e recurso para enfrentar o adoecimento (Almeida, Rezende, Schall \& Modena, 2010); (2) a dimensão do cuidado ético, caro ao profissional psicólogo em diálogo com o princípio da beneficência da ética profissional (Amaral, Avelar \& Santos, 2018); e (3) a vivência do cuidador (psicólogo) no campo de Saúde (Muhl \& Holanda, 2016).

A religiosidade foi reconhecida por Almeida et al. (2018) como auxílio para os adoecidos darem um sentido ao adoecimento, lutarem pela cura com esperança, superarem as mudanças e se sentirem ativos no tratamento. Amaral, Avelar e Santos (2018) ressaltam as instituições de saúde como espaço social favorável para se compartilhar experiências singulares e coletivas. Nesse espaço, o psicólogo possibilita e acompanha os sujeitos no processo de cuidado ético. A oferta da atenção psicológica faz parte da construção de uma prática orientada pelo princípio bioético da beneficência e é essencial para a promoção da qualidade de vida.

Muhl e Holanda (2016) buscaram compreender as vivências cotidianas dos psicólogos que atuam em Saúde Mental Pública. A pesquisa destacou a dualidade na experiência desses profissionais quanto à satisfação versus frustração, identificação com a área de saúde mental versus designação aleatória para o cargo, legislação versus realidade do serviço, e vida profissional versus vida pessoal. Perante essas dualidades, para Muhl e Holanda (2016), "ser- psicólogo na Rede de Atenção Psicossocial é uma experiência conflituosa, essa é a significação atribuída pelos psicólogos às suas vivências e esse é o principal achado desse estudo” (p. 66).

Chamamos atenção para os modelos de atuação do psicólogo na Saúde identificados nas publicações recuperadas para análise. É necessário refletir criticamente sobre o lugar nuclear do psicólogo e os modelos de atuar nesse campo, como evidenciam Cimino e Leite (2016). A prática do psicólogo na Saúde Pública ocorre em parte ancorada nos saberes 
da psicologia clínica tradicional e aponta para a necessidade de um novo modelo comprometido com a dimensão ético-política da profissão no contexto de saúde coletiva. Sobre a compreensão de sofrimento, os recursos clínicos se mostram insuficientes para responder às queixas, que trazem sofrimentos muito concretos e multifatoriais (familiares, culturais, econômicos, políticos e sociais). Isso colabora para um sentimento de impotência do psicólogo frente às limitações e dificuldades na atuação em contextos de saúde.

Como revelam os resultados apresentados, a atuação do psicólogo nos serviços de saúde no geral ainda é um desafio. Dimenstein (1998), acerca da atuação do psicólogo em UBS, aponta para uma problemática central que são os aportes teóricos e práticos que fundamentam os modelos de atuação na Atenção Primária à Saúde, ou seja, a formação do profissional para esse campo de atuação é inadequada. Diante disso, a transposição do modelo hegemônico da atuação clínica para a saúde pública se mostra recorrente. Há, pois, necessidade de transformação da cultura profissional para ampliar os modelos de atuação.

Mais recentemente, Penido (2013) apresentou o apoio matricial como estratégia e ferramenta no cuidado em saúde coletiva em contextos de atenção primária. Segundo a autora, o apoio matricial diz respeito também às práticas compartilhadas em saúde num trabalho em equipe multiprofissional, que busca conhecer e estabelecer vínculo de acolhimento e relação com usuários, com famílias, com o território a partir da UBS. Assim, devese pensar criticamente sobre o papel nuclear do psicólogo na equipe de saúde e sua relação com o campo produtivo de saúde em equipe. Sobre isso, Campos (2000) discute o campo e o núcleo de saberes e práticas da saúde coletiva. O campo seria um espaço de limites imprecisos onde a profissão buscaria apoio para cumprir tarefas teóricas e práticas, enquanto o núcleo demarcaria a identidade profissional.

Com relação à atuação do psicólogo no contexto hospitalar, Bruscato, Amorim, Haberkorn e Santos (2010) discutem que ela ocorre essencialmente ligada às equipes multiprofissionais e envolve a triangulação psicólogo-instituição-paciente. Nessa direção, Amorim (2010) aborda a intervenção psicológica no ambiente hospitalar. Enfatiza que o plano de atuação decorre do conhecimento das demandas e das possibilidades reais. A não ser pela importância do protagonismo do sujeito atendido, a intervenção psicológica hospitalar é distinta do modelo clínico tradicional, ainda que seja um modelo utilizado.

À guisa de arremate, os resultados encontrados neste estudo concordam com a posição de Campos (2000), para quem a saúde seria um processo de produção, um bem a ser conquistado, social e historicamente. Também o autor e os achados vislumbram que os profissionais de saúde deveriam ser "comprometidos com a defesa da vida" (p. 228). Na seara da saúde coletiva, os profissionais deveriam trabalhar com sujeitos (grupos) concretos, constituídos social e culturalmente. Finalmente, o autor e as pesquisam apontam para a reconstrução da saúde coletiva com ênfase nos fortalecimentos dos sujeitos individuais e coletivos, sem primazia à doença ou às estruturas.

\section{Considerações Finais}

A Psicologia da Saúde, apesar de sua história de constituição, mostra-se em construção. A atuação do psicólogo no campo de Saúde é permeada pela influência da Psicologia Clínica, da Psicologia Hospitalar e da Psicologia Social, porém a Psicologia da Saúde constitui campo amplo com sua especificidade. As pesquisas revelam que os modelos de atuação do psicólogo no campo de Saúde constituem um desafio e requerem reflexão crítica acerca do núcleo específico da atuação do psicólogo nos contextos de saúde.

A definição de saúde presente nos estudos concerne ao modelo biopsicossocial. Todavia, vários estudos destacam a importância da religiosidade na promoção de saúde. Há unanimidade em buscar compreender a produção subjetiva a partir das vivências: o significado da experiência (sentido hermenêutico), de usuários de serviços de saúde e dos profissionais. Os estudos, pois, focalizam a produção de saúde como processo de cuidado em construção coletiva.

A Fenomenologia se mostra de suma importância como reflexão filosófica para o campo de Psicologia da Saúde, por propiciar a compreensão dos fenômenos em saúde por meio dos significados atribuídos pelos sujeitos às experiências vivenciais. Nesse caso, a importância primeira é do precursor do projeto da Fenomenologia como busca da essência, que foi Edmund Husserl, seguido pelos discípulos dele, como Edith Stein, Martin Heidegger e Emannuel Lévinas.

O método fenomenológico utilizado nos artigos encontrados oferece a possibilidade de desenvolver conhecimento de forma qualitativa em Psicologia da Saúde, porém com variações hermenêuticas em relação ao proposto por Husserl. É importante destacar que não foi encontrado nenhum estudo sobre a "fenomenologia da sáude" ou "fenomenologia psicológica da saúde", ou mesmo próximo daquilo que Husserl concebeu como "Psicologia Fenomenológica”. Além disso, por mais que tenhamos discutido a relação da Fenomenologia com a Psicologia, este estudo não teve como foco a "Psicopatologia fenomenológica", de tal formaque sugerimos pesquisas sobre esse tema.

Por fim, atingimos o objetivo proposto no estudo, já que a Fenomenologia oferece valiosas 
contribuições para o desenvolvimento da Psicologia da Saúde. Ademais, o crivo desta pesquisa se direcionou ao psicólogo como profissional da saúde, o que também é um limite no sentido de não incluir artigos correlacionando Fenomenologia e Saúde com ênfase em equipes de profissionais da área da saúde. Acreditamos que novos estudos que englobem o olhar sobre equipes multiprofissionais na relação Fenomenologia e Saúde são imprescindíveis.

\section{Referências}

Ales Bello, A. (2017). Introdução à fenomenologia (Jatinta Turolo Garcia; Miguel Mahfoud, Trads.). Bauru, SP: Edusc.

Almeida, R. A., \& Malagris, L. E. N. (2011). A prática da psicologia da saúde. Rev. SBPH, 14 (2), 183202 .

Almeida, S. S. L. de, Rezende, A. M., Schall, V. T., \& Modena, C. M. (2010). Os sentidos da corporeidade em ostomizados por câncer. Psicologia em Estudo, Maringá, 15 (4), 761-769.

Alves, R., Santos, G., Ferreira, P., Costa, A., \& Costa, E. (2017). Atualidades sobre a Psicologia da Saúde e a Realidade Brasileira. Psicologia, Saúde $\mathcal{\sigma}$ Doenças, 18 (2), 545-555.

Amaral, V. R. F. A., Avelar, T. C. de, \& Santos, S. E. B. (2018). Mulheres transplantadas renais: um olhar fenomenológico existencial para a experiência da gestação. Phenomenological Studies - Revista da Abordagem Gestáltica, 24 (1), 3-14.

Amorim, S. F. (2010). Intervenção psicológica no Hospital Geral. Em W. L. Bruscato, C. Beneditti \& S. R. A. Lopes (Orgs), A prática da psicologia hospitalar na Santa Casa de São Paulo: novas páginas em uma antiga história (pp. 69-78). São Paulo: Casa do Psicólogo.

Angerami-Camon, V. A. (2011). O Ressignificado da Prática Clínica e suas Implicações na Realidade da Saúde. Em Angerami-Camon, V. A. (Org.), Psicologia da Saúde: um novo significado para a prática clínica (pp. 1-15). São Paulo: Cengage Leraning.

APA - American Psychological Association. (2018). Acesso em 03/10/2018. Recuperado em 03 de outubro, 2018, de http://www.health-psych. org/.

Batistella, C. (2007). Abordagens Contemporâneas do Conceito de Saúde. Em Fonseca, A. F., \& Corbo, A. D. (Org.), O Território e o Processo Saúde-Doença. Rio de Janeiro: EPSJV, Fiocruz, 51-86.
Biagi-Borges, A. L., Tonon, L., Scorsolini-Comin, F., \& Peres, R. S. (2015). Pesquisa em Psicologia da Saúde: avaliação da produção de um programa de Pós-Graduação. Gerais: Revista Interinstitucional de Psicologia, 8 (1), 143-155.

Brasil (1988). Constituição Federal da República. Brasília: Governo Federal.

Brito, R. F., Avelar, T. C. de, Caldas, M. T., Santos, L. F., Castro, F. P. S., \& Prado, B. C. (2017). A Experiência da Primeira Sessão de Hemodiálise: uma Investigação Fenomenológica. Revista da Abordagem Gestáltica - Phenomenological Studies, 23 (1), 3- 9.

Bruscato, W. L., Amorim, S. F., Haberkorn, A., \& Santos, D. A. (2010). O cotidiano do psicólogo no Hospital Geral. Em W. L. Bruscato, C. Beneditti \& S. R. A. Lopes (Orgs), A prática da psicologia hospitalar na Santa Casa de São Paulo: novas páginas em uma antiga história (pp. 43-51). São Paulo: Casa do Psicólogo.

Buss, P. M. (2017). Uma Introdução ao Conceito de Promoção da Saúde. Em: D. Czeresnia, \& C. M. Freitas. Promoção da Saúde: conceitos, reflexões, tendências (pp. 15-38). Rio de Janeiro: Editora Fiocruz.

Campos, G. W. S. (2000). Saúde pública e saúde coletiva: campo e núcleo de saberes e práticas. Ciência \& Saúde Coletiva, 5(2), 219-230.

Castro, E. K., \& Bornholdt, E. (2004). Psicologia da Saúde x Psicologia Hospitalar: Definições e Possibilidades de Inserção Profissional. Psicologia Ciência e Profissão, 24 (3), 48-57.

Castro, G. J. M. de, \& Costa, M. L. (2018). A Invenção do Sujeito. Psicologia: Ciência e Profissão, 38 (2), 391-402.

Castro, T. G., \& Gomes W. B. (2011). Movimento fenomenológico: Controvérsias e perspectivas na pesquisa psicológica. Psicologia: Teoria e Pesquisa, 27(2), 233-240.

Cimino, A. P. N, \& Leite, D. F. C. C. S. (2016). Psicologia e Saúde Pública: Cartografia das Modalidades de Prática Psicológica nas Policlínicas. Revista Psicologia e Saúde, 8 (1), 14- 23.

CFP - Conselho Federal de Psicologia. (2007). Resolução 13/07. Recuperado em 03 de outubro, 2018, de http://www.pol.org.br.

Costa, M. L., \& Bernardes, A. G. (2012). Produção de Saúde como Afirmação de Vida. Saúde Soc. São Paulo, 21 (4), 822-835. 
Costa, M. L., \& Castro, G. J. M. (2017). A Fenomenologia e a Pesquisa em Psicologia da Saúde. Rev. Nufen: Phenom. Interd., 9 (3), 127-139.

Cruz, A. P. C., \& Cunha, M. S. (2015). Formação em Psicologia da Saúde: Tensões e Potências no Campo Interdisciplinar. Revista Nufen: Phenom. Interd., 7 (2), 137-151.

Declaração de Alma-Ata. Conferência Internacional sobre cuidados primários de saúde; 6-12 de setembro 1978; Alma-Ata; USSR. Em: Ministério da Saúde. Secretaria de Políticas de Saúde. (2001). Projeto Promoção da Saúde. Brasília (DF): Ministério da Saúde.

Demarzo, M. M. P., \& Aquilante, A. G. (2008). Saúde escolar e escolas promotoras de saúde. Em Programa de Atualização em Medicina de $\mathrm{Fa}$ mília e Comunidade (pp. 49-76). Porto Alegre: Artmed/Pan-Americana.

Dimenstein, M. D. B. (1998). O psicólogo nas Unidades Básicas de Saúde: desafios para a formação e atuação profissionais. Estudos de Psicologia, 3 (1), 53-81.

Feijoo, A. M. L. C., \& Goto, T. A. (2016). É Possível a Fenomenologia de Husserl como Método de Pesquisa em Psicologia? Psicologia: Teoria e Pesquisa, 32(4), 1-9.

Feijoo, A. M. L. C., \& Mattar, C. M. (2014). A Fenomenologia como Método de Investigação nas Filosofias da Existência e na Psicologia. Psicologia: Teoria e Pesquisa, 30 (4), 441- 447.

Giorgi, A. (2006). Difficulties encountered in the application of the phenomenological method in the social sciences. Análise Psicológica, 3 (24), 353-361.

Giorgi, A. (2009). The descriptive phenomenological method in psychology: A modified husserlian approach. Pittsburgh, PA: Duquesne University Press.

Giorgi. A., \& Sousa, D. (2010). Método fenomenológico de investigação em psicologia. Lisboa: Fim de século.

Gonçalves, L. O.; Farinha, G. M. \& Goto. T. A. (2016). Plantão psicológico em unidade básica de Saúde: Atendimento em abordagem humanista-fenomenológica. Revista deabordagem gestáltica - Phenomenological Studies, 23 (2), 225-232.

Goto, T. A. (2015). Introdução à psicologia fenomenológica - A nova psicologia de Edmund Husserl. São Paulo: Paulus.
Goto, T. A., Costa, I. I. da, \& Schievano, B. A. (2019). Vivências psicológicas de homens que buscam profissionais do sexo. Uma proposta de análise psicológico-fenomenológico. Revista de Psicologia, 10(1), 90 - 104. Recuperado em 2 de julho, 2019, de http://www.periodicos.ufc.br/ psicologiaufc/article/view/33703.

Goto, T. A., \& Moraes, M. A. B. (2016). A Concepção de Fenomenologia para Edith Stein. Revista Filosófica São Boaventura, 10 (2), 51-66.

Grzibowski, S. (2016). Intuição e percepção em Husserl: Leituras de Emmanuel Lévinas. Rev. $\mathrm{Nu}$ fen: Phenom. Interd., 8 (2), 65-76.

Husserl, E. (2000). A idéia da fenomenologia. Lisboa: Edições 70. (Original publicado em 1907).

Husserl, E. (2001). Psychologie phénoménologique (P. Cabestan, N. Depraz \& A. Mazzu, Trad.). Paris: Vrin. (Original publicado em 1925).

Husserl, E. (2006). Ideias para uma fenomenologia pura e para uma filosofia fenomenológica: introdução geral a fenomenologia pura (Carlos Alberto Ribeiro de Moura, Trad.). Aparecida, SP: Ideias \& Letras. (Original publicado em 1913).

Husserl, E. (2007). Investigações lógicas (Vols. 1-2; P. Alves \& C. Marujão, Trad.). Lisboa: Centro de Filosofia da Universidade de Lisboa. (Original publicado em 1901).

Husserl, E. (2012). A crise das ciências europeias e a fenomenologia transcendental: uma introdução à filosofia fenomenológica. Rio de Janeiro: Forense Universitária. (Original publicado em 1954).

Matarazzo, J. (1980). Behavioral health and Behavioral Medicine. Frontiers for a new Health Psychology. American Psychologist, 35 (9), 807-817.

Mattar, C. M., Aleixo, A. L. C., Aizman, N. C., Feijoo, A. M. L. C. de, Gomes, C. L. M., \& Maués, P. Z. (2016). Da tradição em Psicossomática às considerações da Daseinsanálise. Psicologia: Ciência e Profissão, 36 (2), 317-328.

Mortari, L. (2018). Filosofia do cuidado. São Paulo: Paulus.

Muhl, C., \& Holanda, A. F. (2016). "Duas Faces da Mesma Moeda”: Vivência dos Psicólogos que Atuam na Rede de Atenção Psicossocial. Revista da Abordagem Gestáltica - Phenomenological Studies. 22 (1), 59-67. 
Penido, C. M. F. (2013). Apoio matricial em saúde mental no contexto da saúde coletiva. Em

S. Paulon \& R. Neves (Orgs), Saúde Mental na Atenção Básica: a territorialização do cuidado (pp. 17-38). Porto Alegre: Sulina.

Remor, E. (1999). Psicologia da saúde: Apresentação, origens e perspectivas. Psico, 30 (1), 205-217.

Ribeiro, J. L. P. (2011). A Psicologia da Saúde. Em R. F. Alves (Org.), Psicologia da saúde: teoria, intervenção e pesquisa [online] (pp. 23-64). Campina Grande: EDUEPB.

Rocha, R. M. G., \& Cardoso, C. L. (2017). A experiência fenomenológica e o trabalho em grupo na saúde mental. Psicologia \& Sociedade, 29, 1-10.

Rodríguez, J., \& Garcia, J. A. (1996). Psicología social de la salud. Em J. L. Álvaro, A., \& Torregrosa, J. R. (Orgs.). Psicología social aplicada (pp. 351379). Madrid: McGraw-Hill.

Rodríguez-Marín, J. (1995). Psicología social de la salud. Madrid: Editorial Síntesis.

Roso, A. (2007). Psicologia social da saúde: tornamo-nos eternamente responsáveis por aqueles que cativamos. Aletheia, 26, 80-94.

Rumin, C. R. (2013). Notas para a História da Psicologia da Saúde. Estudos Interdisciplinares em Psicologia, 4 (1), 30-45.

San Martin, J. (2008). La fenomenologia de Husserl como utopía de la razón. Introducción a la fenomenología. Madrid: UNED.

Scliar, M. (2007). História do Conceito de Saúde. PHYSIS: Rev. Saúde Coletiva, 17 (1), 29- 41.

Sebastiani, R. W. (2011). Histórico e evolução da psicologia da saúde numa perspectiva latinoamericana. Em V. A. Angerami-Camon (Org.), Psicologia da Saúde: um novo significado para a prática clínica (pp. 1-15). São Paulo: Cengage Leraning.

Silva, N. H. L. P. da, \& Cardoso, C. L. (2013). Contribuições da fenomenologia de Edith Stein para a atuação do psicólogo nos Núcleos de Apoio à Saúde da Família (NASF). Rev. Latinoam. Psicopat. Fund., São Paulo, 16 (2), 246-259.
Spiegelberg, H. (1982). The phenomenological movement: a historical introduction. Boston: Martinus Nihjhoff.

Spink, M.J. P. (2003). Psicologia Social e Saúde. Petrópolis: Vozes.

Teixeira, C. F. (2006). Promoção da saúde e SUS: um diálogo pertinente. Em: C. F. Teixeira, \& J. P. Solla (Orgs). Modelo de atenção à saúde: vigilância e saúde da família (pp. 85- 108). Salvador: Editora EDUFBA.

Vendrusculo, J. (2012). Atendimento psicológico em instituições: da tradição àfenomenologia existencial. Estudos e Pesquisas em Psicologia, Rio de Janeiro, 12 (3), 883-896.

Westphal, M. F. (2012). Promoção de saúde e prevenção de doenças. Em: G. W. de S. Campos de S. et al. (Orgs). Tratado de saúde coletiva (pp. 681717). São Paulo: Hucitec.

Witter, G. P. (2008). Psicologia da Saúde e produção científica. Estudos de Psicologia (Campinas), 25(4), 577-584.

Luís Vicente Caixeta (Orcid 0000-0002-6512-689X), Universidade Federal de Uberlândia (UFU). E-mail: luisvicentecaixeta@gmail.com

Renata Fabiana Pegoraro (Orcid 0000-0001-60525763), Universidade Federal de Uberlândia. E-mail: rfpegoraro@yahoo.com.br

Tommy Akira Goto (Orcid 0000-0003-4972-7801), Universidade Federal de Uberlândia. E-mail: tommy@ufu.br

Recebido em 07.09.2019 Primeira Decisão Editorial em 25.08.2020 Segunda Decisão Editorial em 12.04.2021 Aceito em 18.04.2021 